\title{
Plasticity of basal ganglia neurocircuitries following perinatal asphyxia: effect of nicotinamide
}

\author{
Verena Klawitter • Paola Morales • Diego Bustamante • \\ Sonia Gomez-Urquijo • Tomas Hökfelt • \\ Mario Herrera-Marschitz
}

\begin{abstract}
The potential neuroprotection of nicotinamide on the consequences of perinatal asphyxia was investigated with triple organotypic cultures. Perinatal asphyxia was induced in vivo by immersing foetuses-containing uterine horns removed from ready-to-deliver rats into a water bath for $20 \mathrm{~min}$. Sibling caesarean-delivered pups were used as controls. Three days later tissue from substantia nigra, neostriatum and neocortex was dissected and placed on a coverslip.
\end{abstract}

\author{
V. Klawitter $\cdot$ P. Morales $\cdot$ D. Bustamante $\cdot$ \\ M. Herrera-Marschitz ( $\square)$ \\ Programme of Molecular and Clinical Pharmacology, \\ ICBM, Medical Faculty, University of Chile, \\ PO Box 70000 Santiago 7, Chile \\ e-mail:mh-marschitz@med.uchile.cl \\ V. Klawitter \\ e-mail: vklawitter@med.uchile.cl \\ P. Morales \\ e-mail: pmorales@med.uchile.cl \\ D. Bustamante \\ e-mail: dbustama@med.uchile.cl \\ S. Gomez-Urquijo \\ Department of Neuroscience, Faculty of Medicine, \\ University of the Basque Country, 48940 Leioa, \\ Biscay, Spain \\ e-mail: soniam.gomez@ehu.es \\ T. Hökfelt \\ Department of Neuroscience, \\ Karolinska Institutet, Stockholm, Sweden \\ T. Hökfelt \\ e-mail: Tomas.Hokfelt@ki.se
}

After a month, the cultures were processed for immunocytochemistry and phenotyped with markers against the NMDA receptor subunit NR1, tyrosine hydroxylase $(\mathrm{TH})$, or neuronal nitric oxide synthase (nNOS). Some cultures were analysed for cell viability. Nicotinamide $(0.8 \mathrm{mmol} / \mathrm{kg}$, i.p.) or saline was administered to asphyxia-exposed and caesarean-delivered control pups 24,48 and $72 \mathrm{~h}$ after birth. Perinatal asphyxia produced a decrease of cell viability in substantia nigra, but not in neostriatum or neocortex. Immunocytochemistry confirmed the vulnerability of the substantia nigra, demonstrating that there was a significant decrease in the number of NR1 and TH-positive $(+)$ cells $/ \mathrm{mm}^{2}$, as well as a decrease in the length of $\mathrm{TH}^{+}$ processes, suggesting neurite atrophy. In control cultures, many $\mathrm{nNOS}^{+}$cells were seen, with different features, regional distribution and cell body sizes. Following perinatal asphyxia, there was an increase in the number of nNOS $^{+}$cells $/ \mathrm{mm}^{2}$ in substantia nigra, versus a decrease in neostriatum including reduced neurite length, and no apparent changes in neocortex. The main effect of nicotinamide was seen in the neostriatum, preventing the asphyxia-induced decrease in the number of nNOS ${ }^{+}$cells and neurite length. Nicotinamide also prevented the effect of perinatal asphyxia on TH-positive neurite length. The present results support the idea that nicotinamide can prevent the effects produced by a sustained energy-failure condition, as occurring during perinatal asphyxia.

Keywords Perinatal asphyxia $\cdot$ Basal ganglia . Nicotinamide $\cdot$ Poly (ADP-ribose) polymerase-1 (PARP-1) · Organotypic cultures · Neuroprotection · Rat 


\section{Abbreviations}

AIF Apoptosis-inducing factor

AN Nicotinamide-treated, asphyxia-exposed

AS Saline-treated, asphyxia-exposed

BCIP/NBT 5-Bromo-4-chloro-3-indolyl phosphate/ nitroblue tetrazolium

BSA Bovine serum albumin

Calcein-AM Calcein-acetoxymethyl ester

CN Nicotinamide-treated, caesarean-delivered

CS Saline-treated, caesarean-delivered

Cx Neocortex

DA Dopamine

DIV Days in vitro

DMEM Dulbecco's modified Eagle medium

ERCC2 Excision repair cross-complementary rodent repair group 2

EthD-1 Ethidium-homodimer

$\mathrm{H}$ Kruskal-Wallis factor for multiple comparison test

NADPH-d Nicotinamide adenine dinucleotide

phosphate diaphorase

NF- $\kappa B \quad$ Nuclear factor $\kappa B$

NMDA $\quad N$-methyl-D-aspartate

NO Nitric oxide

eNOS Endothelial NO synthase

iNOS Inducible NOS

nNOS Neuronal NOS

NR1 Subunit 1 of the NMDA receptor

PARP Poly(ADP-ribose) polymerase

PBS Phosphate-buffered saline

PF Para-formaldehyde

SN Substantia nigra

Str Neostriatum

TH Tyrosine hydroxylase

TNF- $\alpha \quad$ Tumoral necrosis factor $\alpha$

XRCC1 X-ray cross complementary factor 1

\section{Introduction}

Asphyxia interrupts oxygen availability, resulting in increased anaerobic metabolism, decreased production of energy-rich phosphate compounds, and interruption of membrane conductance. When sustained, the insult can threaten DNA integrity (Kihara et al. 1994; Akhter et al. 2001), triggering a cascade of events buffering the menace to the stability of the genome, notably the immediate activation of poly(ADP-ribose) polymerase-1 (PARP-1) and PARP-2, which are members of a large family of PARPs (Amé and Spenlehauer de Murcia 2004).

When DNA damage is mild, PARP-1 is involved in the maintenance of chromatin integrity, by signalling cell-cycle arrest and by reacting with DNA repairing enzymes, such as X-ray cross complementing factor 1 (XRCC1) (Green et al. 1992) and DNA-dependent protein kinase (de Murcia and Menissier de Murcia 1994). Severe perinatal asphyxia produces DNA breaks (Kihara et al. 1994), and increases the expression of the XRCC1 and excision repair cross-complementing rodent repair group 2 (ERCC2) (Chiappe-Gutierrez et al. 1998) genes. Like XRCC1, ERCC2 is involved in repairing DNA damage (Sung et al. 1993). When DNA is damaged, PARP-1 is over-activated (Berger 1985), resulting in $\mathrm{NAD}^{+}$exhaustion and energy crisis (Ying et al. 2005), leading to a caspase-independent apoptosis, via translocation of the mitochondrial pro-apoptotic protein, Apoptosis-inducing factor (AIF). PARP-1 is involved in the regulation of cell proliferation and differentiation, and may modulate the transcription of several inflammatory signals, including nuclear factor $\kappa \mathrm{B}(\mathrm{NF}-\kappa \mathrm{B})$ (Hassa and Hottinger 1999). It has been suggested that PARP-1 modulates nitric oxide (NO) synthesis, via inducible NO synthase (iNOS), but also via the neuronal isoform of NOS (nNOS) (Hwang et al. 2002; Mishra et al. 2003; Hortobagyi et al. 2003). Hence, PARP-1 inhibition has emerged as the main target for neuroprotection following hypoxic or ischemic insults (see Virag and Szabo 2002).

There is also evidence that PARP inhibition can be deleterious, depending upon the level of $\mathrm{NAD}^{+}$cellular content. In the presence of $\mathrm{NAD}^{+}$, PARP inhibition sensitises cells to DNA damage, increasing cell death (Nagayama et al. 2000), and apoptosis (Saldeen and Welsh 1998) in rapidly dividing cells, perhaps by blocking the access of DNA to replication or repair enzymes, promoting G2 arrest followed by p53-independent apoptosis (Saldeen et al. 2003), resulting in inhibition of cell proliferation.

Nicotinamide has been proposed to protect against oxidative stress produced by hypoxia or ischemia in neonatal rat brain, by replacing $\mathrm{NADH}$ or $\mathrm{NAD}^{+}$ (Zhang et al. 1995). We have reported that neonatal treatment with nicotinamide prevents several deficits in monoamine levels induced by perinatal asphyxia (Bustamante et al. 2003), including dopamine release monitored with in vivo microdialysis 3 months after birth (Bustamante et al. 2006), supporting the idea that nicotinamide can constitute a therapeutic strategy against the long-term deleterious consequences of perinatal asphyxia, as already proposed for several other pathophysiological conditions (see Virag and Szabo 2002).

In this paper, we focus on the effect of nicotinamide on basal ganglia neurocircuitries studied in organotypic cultures, a model originally developed by Gähwiler 
(1981), extensively validated by Plenz and Kitai (1996a, b; Plenz et al. 1998), and used for the reconstruction of the neurocircuitries of the basal ganglia (GomezUrquijo et al. 1999). The neuronal phenotype was assessed with markers against: (1) the $N$-methyl-Daspartate (NMDA) receptor subunit 1 (NR1); (2) tyrosine hydroxylase $(\mathrm{TH})$, the rate-limiting enzyme of dopamine (DA) synthesis, and (3) nNOS.

As previously reported (Morales et al. 2003; Klawitter et al. 2005), perinatal asphyxia produces regionally specific neuronal decrease and neurite atrophy in basal ganglia, reconstructed with organotypic cultures. We report here that several of these changes can be reversed by treating the animals with nicotinamide before the explanting procedure. A preliminary version of this work has been published elsewhere (Klawitter et al. 2006).

\section{Experimental procedures}

\section{Perinatal asphyxia}

Pregnant Wistar rats (UChA, bred at a local colony) were anaesthetised with isoflurane USP (Baxter Healthcare Corp, Guayama, Puerto Rico) within the last day of gestation ( G 22) and euthanized by neck dislocation followed by hysterectomy. One or two pups were removed immediately and used as non-asphyxiated caesarean-delivered controls, and the uterine horns containing the remaining foetuses were immersed in a water bath at $37^{\circ} \mathrm{C}$ for $20 \mathrm{~min}$. Following asphyxia, the uterine horns were incised and the pups were removed, and stimulated to breathe. After a 60 min observation period, the pups were given to surrogate dams for nursing, pending further experiments. Three days after birth (P3), the pups were used for preparing organotypic cultures (Morales et al. 2003; Klawitter et al. 2005).

The survival rate produced by severe asphyxia ( $>20 \mathrm{~min}$, at $37^{\circ} \mathrm{C}$ ) was approximately $50 \%$ (HerreraMarschitz et al. 1993; see Bustamante et al. 2006). Each mother had to produce animals for: (1) saline-treated, caesarean-delivered (CS); (2) nicotinamide-treated, caesarean-delivered $(\mathrm{CN})$; (3) saline-treated, asphyxiaexposed (AS), and (4) nicotinamide-treated, asphyxiaexposed (AN) groups. Control and treated pups (P3) were killed pair-wise for preparing organotypic cultures. The number of substantia nigra pieces (approximately four per pup) being the limiting factor for the quantity of cultures per animals. Thus, considering a $50 \%$ success rate, each animal provided two organotypic cultures.
The experimental protocol was approved by a Local National Committee for Ethic Experiments with Laboratory Animals (Protocol CBA\# 0136, FMUCH), endorsing the principles of laboratory animal care (NIH; No. 86-23; revised 1985).

\section{Nicotinamide treatment}

Nicotinamide $(0.8 \mathrm{mmol} / \mathrm{kg}$ [100 mg/kg], i.p.; niacinamide, Sigma, St. Louis, MO, USA) or the corresponding vehicle $(0.9 \% \mathrm{NaCl})$ was administered to asphyxiaexposed or caesarean-delivered pups, 24, 48 and $72 \mathrm{~h}$ after birth. The last dose was given $2 \mathrm{~h}$ before preparing the organotypic cultures.

\section{Organotypic cultures}

Different rat series were used for preparing the cultures. All procedures including medium and drug preparation were performed within the arena of a Laminal Flow Cabinet equipped with UV antibacterial light (Factomet VR24242, Filtro Met Ltda. Santiago, Chile). Following decapitation, the brain was rapidly removed under sterile conditions and stored in a Petri dish containing a Dulbecco's modified Eagle medium (DMEM; GIBCO, Life Technologies AB, Täby, Sweden).

Coronal sections were cut with a microslicer (DTK2000, Dosaka CO, Japan) at mesencephalic (300 $\mu \mathrm{m}$ thick) and telencephalic (350 $\mu \mathrm{m}$ thick) levels in cold DMEM. Samples from substantia nigra, neostriatum and neocortex (frontoparietal cortex) were dissected using the atlas by Foster (1998) as a reference. The dissected tissue was placed on a coverslip (Nunc Thermanox Coverslips; Nunc, Naperville, IL, USA) containing a spread layer of chicken plasma $(25 \mu \mathrm{l})$, and further coagulated by bovine thrombin $(20 \mu \mathrm{l}, 1,000 \mathrm{NIH}$ units in $0.28 \mathrm{ml}$ DMEM; Sigma). The coverslips were then transferred to sterile Nunc flat CT-tubes (Nunc), containing an un-buffered culture medium $(50 \%$ Basal Medium Eagle; 25\% Hanks Balanced Salt Solution, and $25 \%$ horse serum (Gibco BRL), $0.5 \%$ glucose (Sigma), $0.5 \mathrm{mM}$ of L-glutamine (Sigma), and $0.1 \%$ antibiotic or antimycotic (Gibco BRL).

The cultures were grown at $35^{\circ} \mathrm{C}, 10 \% \mathrm{CO}_{2}$ in a Cell Incubator (Model TC2323, ShelLab, Oregon, USA), with a Roller device exposing the cultures to gaseous or water phases every minute. At 3 days in vitro (DIV), $10 \mu \mathrm{l}$ of a mitosis inhibitor cocktail ( $4.4 \mathrm{mM}$ cytosine- $\beta$ D-arabinofuranoside, $4.4 \mathrm{mM}$ uridine and $4.4 \mathrm{mM} 5$ fluoro-2'-deoxyuridine; all from Sigma) was added for $24 \mathrm{~h}$ in order to decrease glial proliferation. The medium was changed every 3-4 days. 
In vitro and ex vivo monitoring

Growth was periodically monitored with an inverted microscope equipped with Hoffmann optic (Nikon T100). Pictures were regularly taken, and at DIV 25 the cultures were fixed with a formalin solution. Alternatively, the cultures were analysed for cell viability at DIV 27, with the LIVE/DEAD ${ }^{\circledR}$ Viability/Citotoxicity kit L3224 (Molecular Probes, Eugene, OR, USA), using ethidium-homodimer (EthD-1) and calcein-acetoxymethyl ester (AM) for labelling dead and alive cells, respectively. For quantification three samples were taken from the core and border of the tissue, focusing on areas presenting the majority of EthD-1 positive cells (see Fig. 1a-f).

\section{Immunocytochemistry}

The cultures were fixed in formalin (4\% para-formaldehyde, PF; Sigma, in $0.1 \mathrm{M}$ of phosphate-buffered saline, PBS, pH 7.4) at $\sim$ DIV 25. After rinsing cycles, endogenous peroxidase activity was blocked with $1 \%$ $\mathrm{H}_{2} \mathrm{O}_{2}$ for $30 \mathrm{~min}$ and rinsed again with PBS. The tissue was then preincubated with $2 \%$ of bovine serum albumin (BSA) (Calbiochem, CA, USA), 0.3\% Triton X-100, in PBS, for $1 \mathrm{~h}$ at $37^{\circ} \mathrm{C}$, and incubated for $72 \mathrm{~h}$ with a mouse monoclonal antibody against NR1 (dilution 1:600; 2\% BSA and $0.3 \%$ Triton X100, in PBS) (Pharmingen, San Diego, CA, USA) in order to characterise a general neuronal phenotype (Petralia et al. 1994). For visualizing TH, the slices were incubated overnight with mouse monoclonal antibody $(1: 300 ; 2 \%$ BSA and $0.3 \%$ Triton X-100, in PBS) (Diasorin, Stillwater, MN, USA). For nNOS, the slices were incubated for $24 \mathrm{~h}$ with a sheep monoclonal antibody $(1: 500,1 \%$ BSA, PBS $/ 0.6 \%$ Triton X-100) (generously donated by Prof. P. Emson). After rinsing, the slices were processed using a Vectastain Elite ABC kit (Vector Laboratories, Burlingame, CA, USA), according to the instructions of the manufacturer, visualizing the reaction with Vector Nova Red (Vector Laboratories). Otherwise, the slices were processed with a streptavidin phosphatase complex for $1 \mathrm{~h}$, rinsed and incubated with a levamisole solution for $15 \mathrm{~min}$ to inhibit endogenous alkaline phosphatases. The reaction was then visualised with a 5-bromo-4-chloro-3-indolyl phosphate/ nitroblue tetrazolium (BCIP/NBT) substrate kit (Vector Laboratories). The sections were dehydrated through graded alcohols, cleared in xylene and coverslipped in Entellan mounting medium (Merck, Darmstadt, Germany).
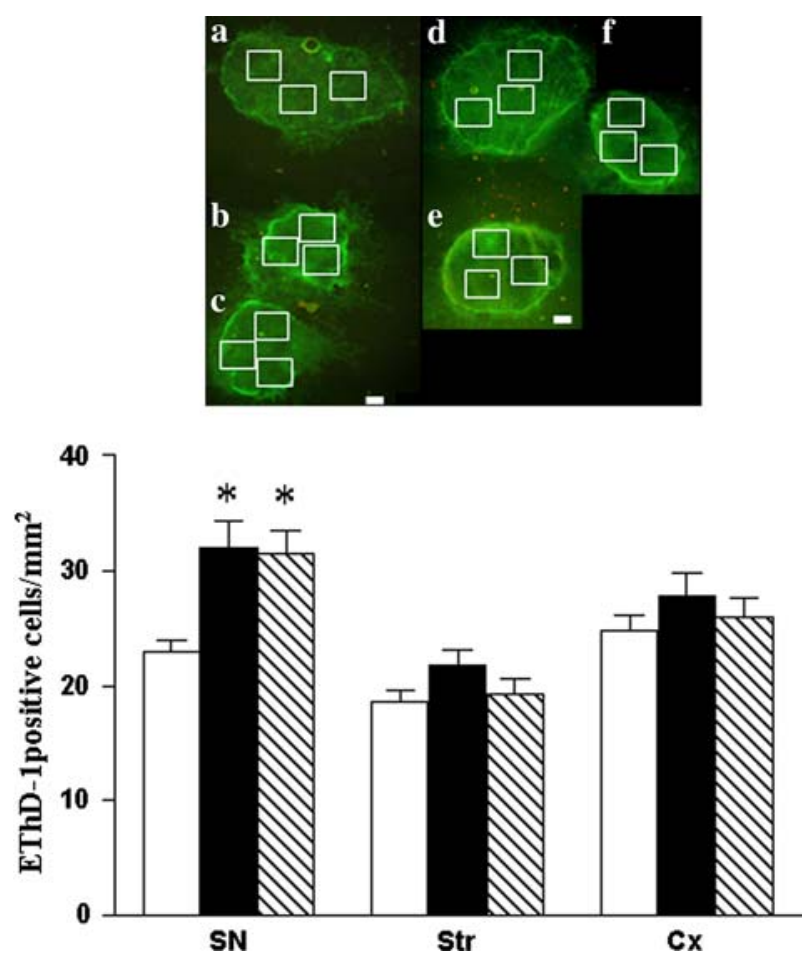

Fig. 1 Quantification of EthD-1 ${ }^{+}$cells observed in triple organotypic ( $S N$ substantia nigra; Str neostriatum; $C x$ neocortex) cultures at DIV 27, from saline-treated, caesarean-delivered (CS; open bars, $n=16$ ), saline-treated, asphyxia-exposed (AS; filled bars, $n=17$ ) and nicotinamide-treated, asphyxia-exposed (AN; hatched bars, $n=10$ ) rats. Multiple comparison analysis (Kruskal-Wallis's ANOVA, $H$ ) revealed significant differences between groups $(H=43.75 ; m, n=3,30)$, allowing post-hoc comparisons, demonstrating a significant increase of EthD $-1^{+}$cells in $\mathrm{SN}$ of cultures from AS and AN, compared to CS animals. No differences were found in Str and Cx. The insert illustrates microphotographs of the sampling procedure in cultures from salinetreated, caesarean-delivered $(a-c)$, and asphyxia-exposed $(d-f)$ animals (cell viability test, Molecular Probes L3224). For each test, three $1 \mathrm{~mm}^{2}$ samples were selected from substantia nigra ( $a$, $d)$, neostriatum $(b, f)$ and neocortex $(c, e)$, in the areas showing the largest number of EthD-1+ cells. The data are means \pm SEM; $* P<0.05$ (Dunn's test, as a post-hoc test). Scale bar $=500 \mu \mathrm{m}$

\section{Quantification}

Quantification was performed directly on the stage of a microscope using appropriate objectives and filters for the corresponding markers (NR1, TH or nNOS), or on pictures taken at $20 \mathrm{X}$ primary magnification. The microphotographs were digitally stored, composed and analysed with Adobe Photoshop (7.0). Positive cells were quantified in $1 \mathrm{~mm}^{2}$ samples using a graded ocular, selecting three areas from the core of each culture showing the largest number of positive cells (see inserts in Figs. 1,3). This selection was required, because the orga- 
notypic cultures are not always characterised by a uniform tissue layer, but part of the issue can sometimes be interrupted by holes, or debris from the culturing procedure. Three parameters were quantified: (1) number of positive cells $/ \mathrm{mm}^{2}$; (2) soma size (diameter, $\mu \mathrm{m}$ ), and (3) neurite length (maximum length, $\mu \mathrm{m}$ ). The measurement of neurite length was restricted to the corresponding tissue, substantia nigra, neostriatum or neocortex. The same parameters were measured pair wise by an investigator blinded to the codes of the culture, explanted from any of the following experimental groups: (1) CS; (2) CN; (3) AS, or (4) AN animals. The values were transferred to an EXCEL matrix for the corresponding quantitative analysis. All data are expressed as means \pm SEM. Multiple comparisons were tested with the ANOVA (H) of Kruskal-Wallis, followed by a post-hoc test when required (GraphPad Prism; version 4.0, 2003; San Diego, CA, USA), using a level of $P<0.05$ as a limit for statistical significance.

\section{Results}

Some cultures (CS, AS, AN) were preserved for cell viability test performed at 27 DIV with the LIVE/DEAD ${ }^{\circledR}$ kit, using Calcein-AM (green fluorescence) and EthD-1 (red fluorescence) for labelling alive and dying cells, respectively. The individual regions were well outlined by a strong green fluorescence, revealing a core with plenty of alive cells. Some red cells could be seen in the core of the tissue, but many more were seen in the gaps between the individual structures.

For quantification, three $1 \mathrm{~mm}^{2}$ areas per structure were selected, trying to cover the areas with the largest density of cells (the insert in Fig. 1 exemplifies the sampling procedure). EThD-1 positive (+) cells seen in the gaps between individual tissues or in holes were not quantified. The quantitative analysis (Fig. 1) revealed a marked increase of EThD- $1^{+}$cells in substantia nigra of cultures from AS ( $\sim 39 \%)$ (filled bars, $n=17)$ and AN $(\sim 37 \%)$ (hatched bars, $n=10$ ), compared to CS (open bars, $n=16)$ animals $(H=43 ; m, n=3,30)$. No differences were detected in neostriatal or neocortical tissue of cultures from saline- or nicotinamide-treated, asphyxia-exposed, compared to control animals (Fig. 1). Some few CN samples were also assayed for cell viability, but no apparent differences were observed; hence reserving the material and giving priority for immunocytochemistry investigating the neuronal phenotype.

The cultures were routinely fixed at 25 DIV and treated for immunocytochemistry. Figure 2 shows microphotographs of neurons and processes labelled with an antibody against NR1 in cultures from CS $(a, b, c)$, AS $(\mathrm{d}, \mathrm{e}, \mathrm{f})$, and $\mathrm{AN}(\mathrm{g}, \mathrm{h}, \mathrm{i})$ animals, in substantia nigra (SN),
Fig. 2 Microphotograph of NMDA NR1 $1^{+}$neurons (dark) observed in organotypic triple cultures at DIV 25 from: saline-treated, caesareandelivered $(C S ; \mathbf{a}-\mathbf{c})$; salinetreated, asphyxia-exposed (AS; $\mathbf{d - f})$, and nicotinamidetreated, asphyxia-exposed $(\mathrm{AN} ; \mathbf{g}-\mathbf{i})$ animals. $(\mathbf{a}, \mathbf{d}, \mathbf{g})$ are microphotographs from $(S N)$; $(\mathbf{b}, \mathbf{e}, \mathbf{h})$ from neostriatum $($ Str $) ;(\mathbf{c}, \mathbf{f}, \mathbf{i})$ from neocortex $(C x)$. Bipolar and multipolar neurons were observed in all regions. Scale bar $=25 \mu \mathrm{m}$

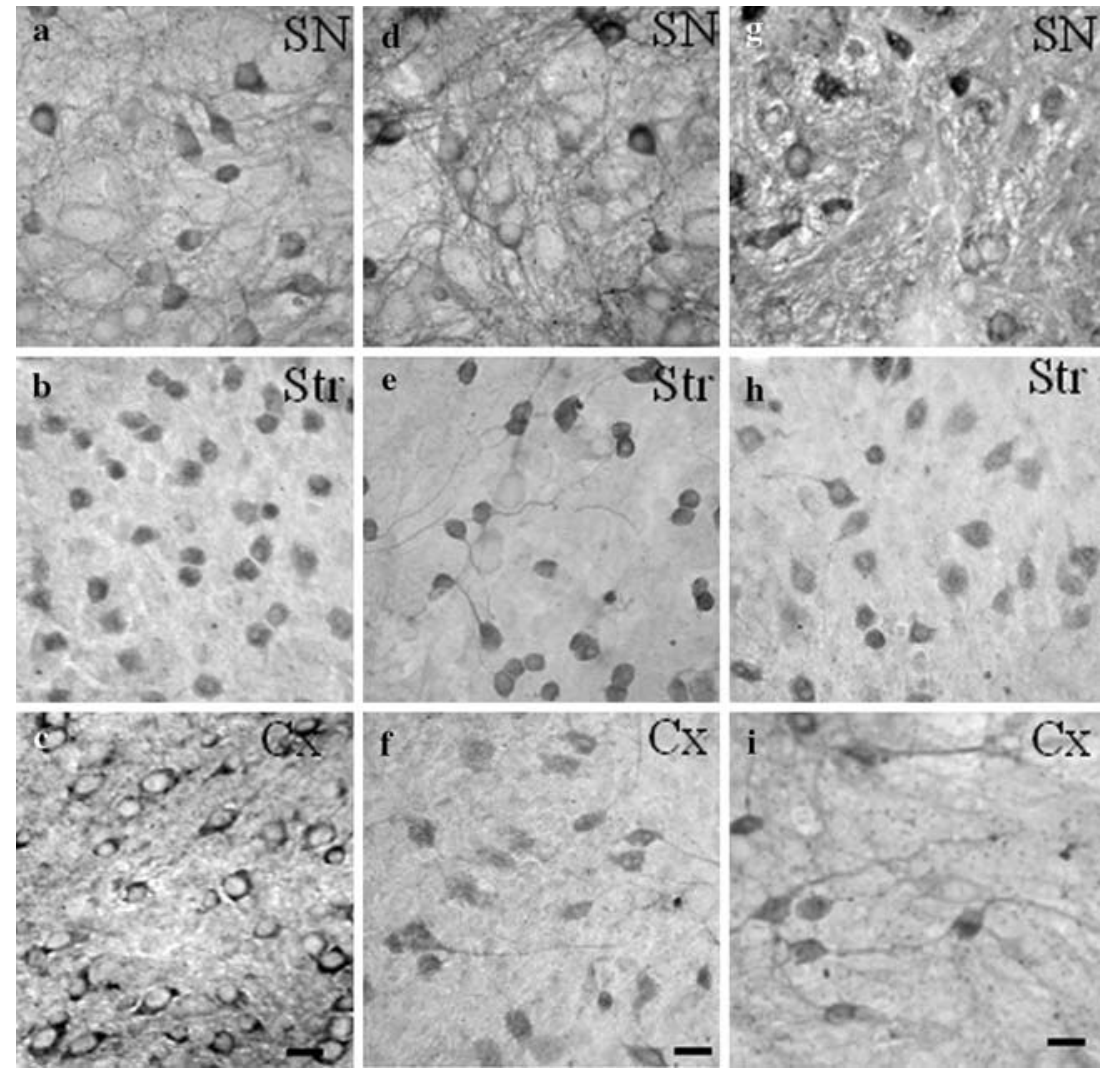



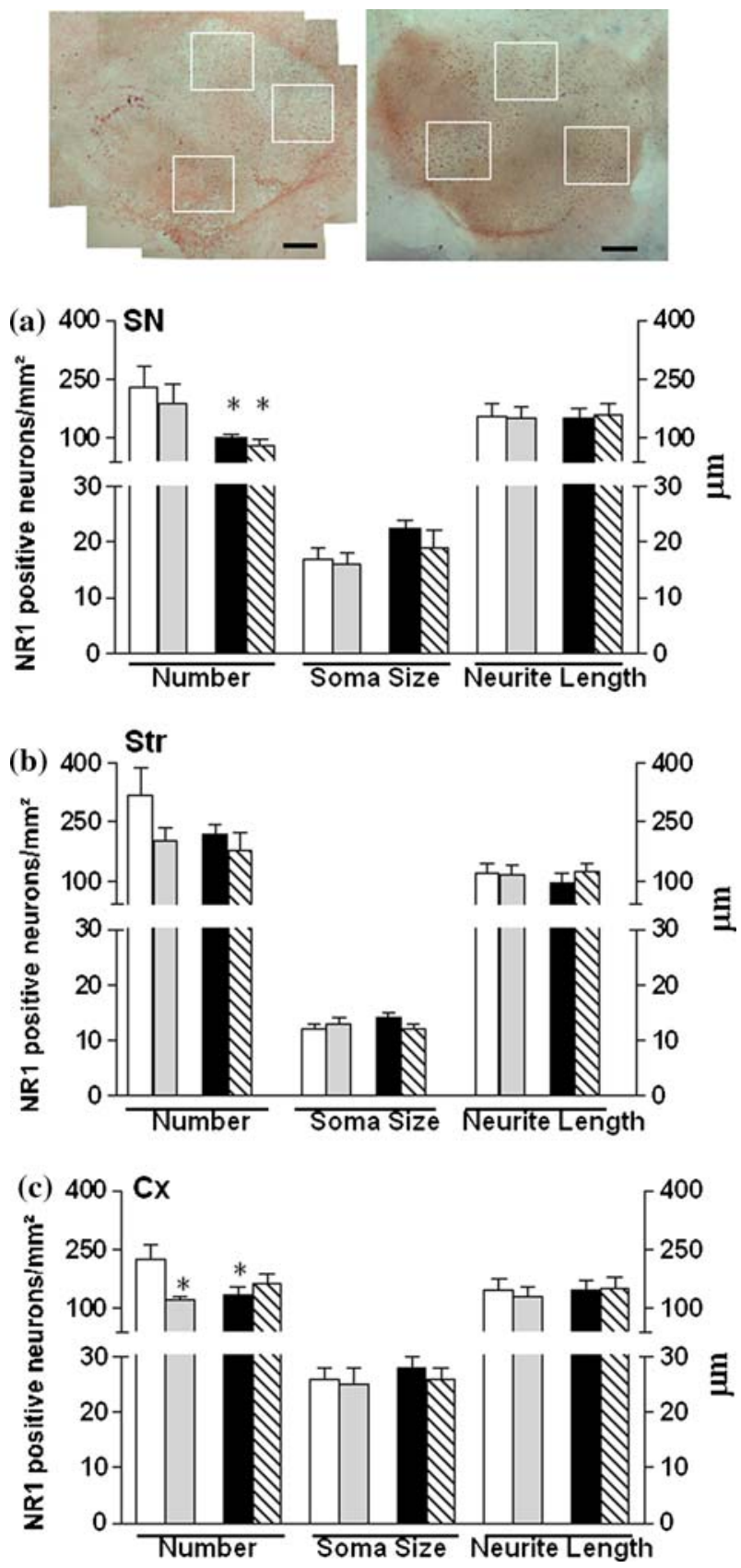

neostriatum (Str) and neocortex $(\mathrm{Cx})$, respectively. Neurons with distinct soma size and processes were evident, with bipolar and multipolar features.

Quantitative analysis was applied for cultures from CS $(n=9-12), \mathrm{CN}(n=6)$, AS $(n=15-17)$ and AN $(n=9-10)$ animals. Three samples of $1 \mathrm{~mm}^{2}$ of area for each region (see insert, Fig. 3) were analysed for: (1) number of neurons $\left(\mathrm{NR} 1^{+}\right.$cells $\left./ \mathrm{mm}^{2}\right)$; (2) size of soma $(\mu \mathrm{m})$, and (3) maximal neurite length $(\mu \mathrm{m})$. Neurite length was estimated in the corresponding region, as long as the NR1 staining could be followed at 40-100X. Multiple comparison analysis revealed significant
-Fig. 3 Quantification of number $\left(\right.$ cells $\left./ \mathrm{mm}^{2}\right)$, soma size $(\mu \mathrm{m})$, and neurite length (maximum length, $\mu \mathrm{m}$ ) of $\mathrm{NR} 1^{+}$neurons in: substantia nigra $(S N)(\mathbf{a})$; neostriatum $(S t r)(\mathbf{b})$, and neocortex $(C x)(\mathbf{c})$ of organotypic triple cultures (DIV 25) from saline-treated, caesarean-delivered (CS; open bars, $n=9-12$ ); nicotinamidetreated, caesarean-delivered (CN; grey bars, $n=6)$; saline-treated, asphyxia-exposed (AS; filled bars, $n=15-17$ ), and nicotinamidetreated, asphyxia-exposed (AN; hatched bars, $n=9-10)$ animals. Multiple comparison analysis (Kruskal-Wallis's ANOVA, $H$ ) revealed significant differences between groups for cell number and soma size ( $H=39.31 ; H=47.2, m, n=4,24$, respectively), allowing post-hoc comparisons. There was a significant decrease in the number of $\mathrm{NR}^{+}$neurons in $\mathrm{SN}$ of cultures from AS and AN compared to CS animals. A significant decrease in cell number was also observed in $\mathrm{Cx}$ of cultures from $\mathrm{AS}$ and $\mathrm{CN}$, but not from AN animals. Data are means $\pm \mathrm{SEM} ; * P<0.05$ (Dunn's test). The insert illustrates the sampling procedure in Str of cultures from AS (figure on the left), and AN (figure on the right) animals. Three $1 \mathrm{~mm}^{2}$ samples were selected from each region showing the largest number of NR1-positive cells. Scale bar $=500 \mu \mathrm{m}$

differences between groups for cell number and soma size $(H=39.31 ; H=47.2, m, n=4,24$, respectively), but not for neurite length $(H=7.9, m, n=4,24)$, allowing, however, post-hoc comparisons. As shown in Fig. 3, there was a significant decrease of $\mathrm{NR} 1^{+}$cell number in substantia nigra of AS ( $\sim 57 \%)$ and AN $(\sim 65 \%)$ versus CS cultures (Fig. 3a). A significant decrease was observed in neocortex of AS ( 41\%), but not of AN cultures. However, a significant decrease was also observed in neocortex of CN $(\sim 46 \%)$ cultures (Fig. 3c). Although no differences of $\mathrm{NR}^{+}$soma size were observed among the experimental groups, the largest $\mathrm{NR} 1^{+}$cells were observed in neocortex $(25-28 \mu \mathrm{m})$, the smallest $\mathrm{NR}^{+}$cells in neostriatum $(12-14 \mu \mathrm{m})$, and medium soma sized cells in substantia nigra $(16-22 \mu \mathrm{m})$. No statistically significant differences were observed regarding $\mathrm{NR}^{+}$neurite length, among any of the experimental groups.

While $\mathrm{TH}^{+}$plexuses and fibres were observed in all regions, $\mathrm{TH}^{+}$soma were only observed in the substantia nigra, with bipolar or multipolar features and variably developed dendrite trees, as shown in Figs. 4 and 5. Several types of $\mathrm{TH}^{+}$neurons were observed in all cultures conditions. $\mathrm{TH}^{+}$neurons with big $(\sim 28 \mu \mathrm{m})$, medium $(\sim 18 \mu \mathrm{m})$ and small $(\sim 9 \mu \mathrm{m})$ soma size were observed, but medium-sized $\mathrm{TH}^{+}$neurons were predominant (Fig. 4). Rich $\mathrm{TH}^{+}$neuritic trees could be seen, extending processes to different planes forming dense networks, probably representing target regions, as exemplified by a culture from the AS group (Fig. 4a, d).

Figure 5 shows $\mathrm{TH}^{+}$cells of cultures from $\mathrm{CS}(\mathrm{a}, \mathrm{d})$, AS (b,e), and AN (c,f) rats. A decrease in the amount of $\mathrm{TH}^{+}$neurons, as well as in neurite length, was observed in AS compared to CS culture, but not in AN; 


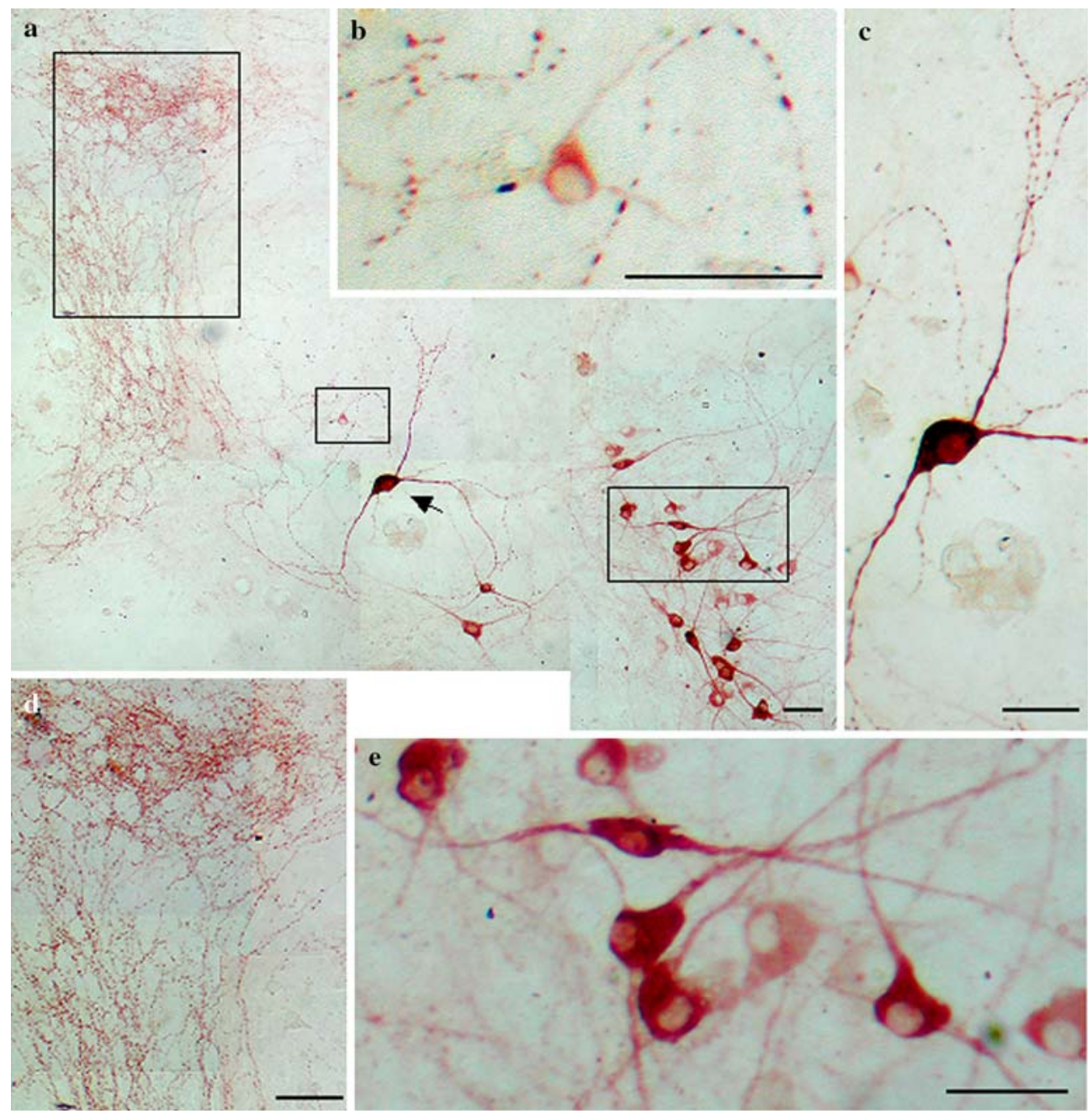

Fig. 4 Microphotographs of $\mathrm{TH}^{+}$neurons (dark) in substantia nigra of a triple organotypic culture from a saline-treated, asphyxiaexposed rat (AS) at DIV 25. Different types of $\mathrm{TH}^{+}$neurons are observed in a composed picture of the same culture (a). A multipolar, $\mathrm{TH}^{+}$neuron with a large soma size (arrow) is seen $(\sim 28 \mu \mathrm{m})$, showing a rich neuritic tree extending to different planes of the culture. A possible axon ascends to an intensively $\mathrm{TH}^{+}$area (large rectangle), branching and forming a dense net-

nicotinamide appearing to prevent the changes in neurite length induced by perinatal asphyxia.

The quantitative and multiple comparison analysis (CS, $n=16-19$; CN, $n=8-13$; AS, $n=17-19$; AN, $n=12-13)$ revealed significant differences between groups for cell number $\left(\right.$ cells $\left./ \mathrm{mm}^{2}\right)$ and neurite length, allowing post-hoc comparisons $(H=10.58$; $H=10.93, m, n=4,32$, respectively). As shown in Fig. 6, there was a statistically significant decrease of $\mathrm{TH}^{+}$cell number in AS $(\sim 65 \%)$ and $\mathrm{AN}(\sim 62 \%)$, compared to CS cultures. The estimation of neurite length was restricted to that observed in the substantia nigra, where a one-by-one characterization was easily done regarding individually labelled neurons. It work, probably representing a target region. A group of $\mathrm{TH}^{+}$medium size neurons $(\sim 18 \mu \mathrm{m})$ is seen to the right (medium rectangle). Small neurons $(\sim 9 \mu \mathrm{m})$ (small rectangle) are also observed. $\mathbf{b}$ is a magnification of the small rectangle depicted in $\mathbf{a} . \mathbf{c}$ is a magnification of the neuron depicted by the arrow in $\mathbf{a}$. d is a magnification of the area depicted by the large rectangle in $\mathbf{a} . \mathbf{e}$ is a magnification of medium size $\mathrm{TH}^{+}$neurons depicted by the medium rectangle in $\mathbf{a}$. Scale bar $=25 \mu \mathrm{m}$

was found that neurite length was decreased in AS $(\sim 55 \%)$, but not in AN cultures, compared to that observed in CS cultures.

Many $\mathrm{nNOS}^{+}$cells were seen in all cultures and regions, with bipolar or multipolar features. The largest number of NOS $^{+}$cells $/ \mathrm{mm}^{2}$ was observed in neocortex, and the lowest in substantia nigra. Figure 7 illustrates $\mathrm{nNOS}^{+}$cells found in neostriatum of an AS culture, with medium $(18-28 \mu \mathrm{m})$ soma size. Figure 8 shows microphotographs illustrating $\mathrm{nNOS}^{+}$cells found in substantia nigra of CS $(a, b)$ and AS $(c, d)$ cultures.

The quantitative and multiple comparison analysis (CS, $n=11-13$; CN, $n=6-7$; AS, $n=7-9 ; \mathrm{AN}, n=9$ ) 

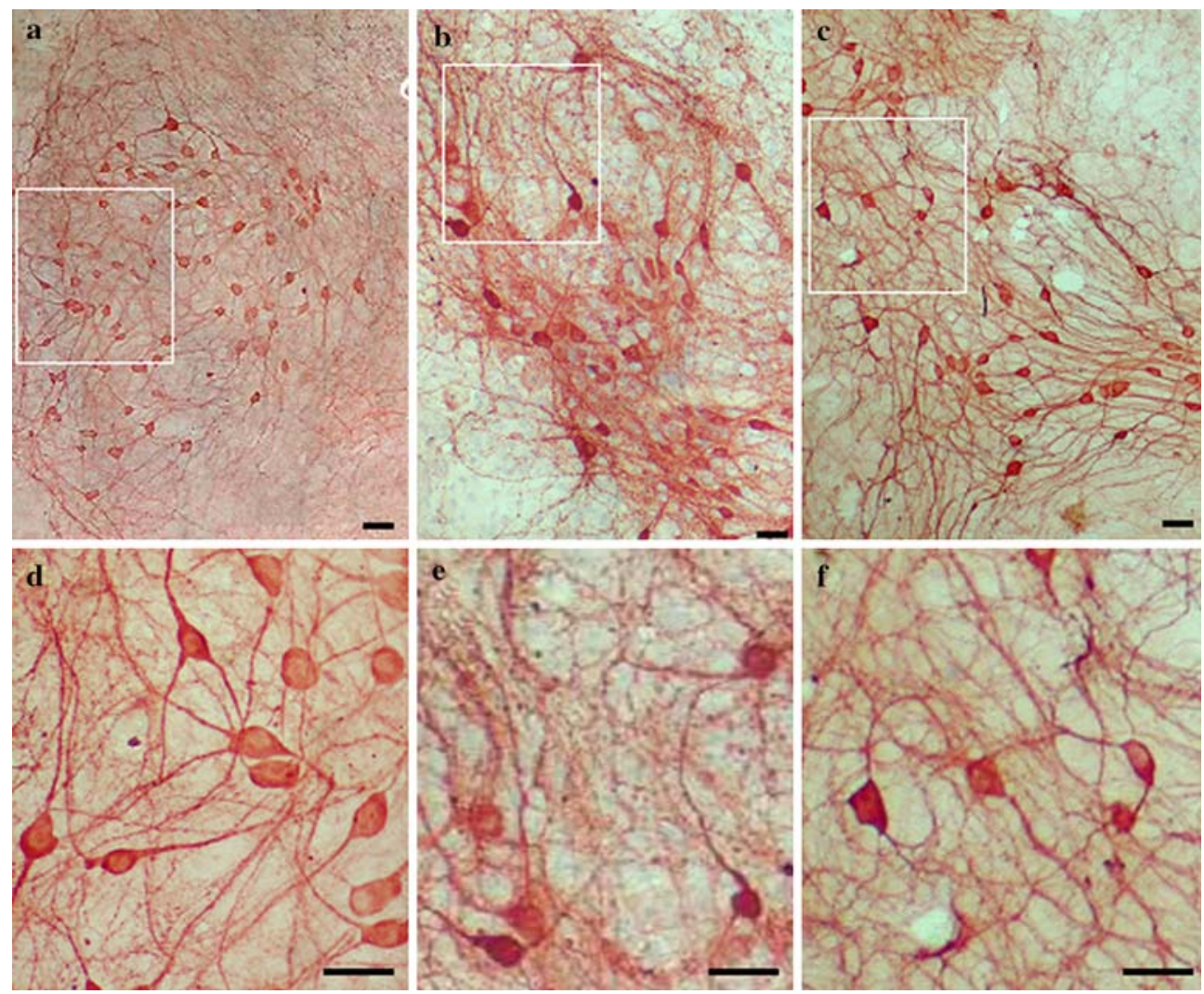

Fig. 5 Microphotographs illustrating $\mathrm{TH}^{+}$neurons seen in substantia nigra of triple organotypic cultures from: saline-treated, caesarean-delivered (CS; a, d); saline-treated, asphyxia-exposed

revealed significant differences between groups for cell number $\left(\right.$ cells $\left./ \mathrm{mm}^{2}\right)(H=39.54 ; m, n=4,44)$, and soma size $(H=44.25 ; m, n=4,44)$, allowing post-hoc comparisons. The number of $\mathrm{nNOS}^{+}$cells in CS cultures was fivefold larger in neocortex $\left(\sim 50\right.$ cells $\left./ \mathrm{mm}^{2}\right)$ or neostriatum $\left(\sim 40\right.$ cells $\left./ \mathrm{mm}^{2}\right)$ than that observed in substantia nigra $\left(\sim 6\right.$ cells $\left./ \mathrm{mm}^{2}\right)$. Furthermore, in CS cultures, $\mathrm{nNOS}^{+}$soma size was larger in neocortex $(36 \pm 1 \mu \mathrm{m})$ than in neostriatum $(26 \pm 2 \mu \mathrm{m})$ or substantia nigra ( $28 \pm 2 \mu \mathrm{m})$ (Fig. 9).

The number of nNOS ${ }^{+}$cells $/ \mathrm{mm}^{2}$ was significantly increased in substantia nigra (greater than fivefold), but decreased $(\sim 70 \%)$ in neostriatum of AS, compared to CS cultures. While the number of $\mathrm{nNOS}^{+}$ cells $/ \mathrm{mm}^{2}$ was also increased in the substantia nigra of AN cultures (greater than fourfold), there was no decrease in neostriatum of AN cultures. Furthermore, compared to $\mathrm{CS}$ cultures, $\mathrm{nNOS}^{+}$neurite length was decreased $(\sim 40 \%)$ in neostriatum of AS, but not in neostriatum of AN cultures (Fig. 9), suggesting that nicotinamide prevented the effect of perinatal asphyxia on $\mathrm{nNOS}^{+}$cell number and neurite length observed in that region. No significant differences were observed in neocortex, despite an apparent
$(\mathrm{AS} ; \mathbf{b}, \mathbf{e})$, and nicotinamide-treated asphyxia-exposed $(\mathrm{AN} ; \mathbf{c}, \mathbf{f})$ rats at DIV 25. d, e, f are a magnification of $\mathbf{a}, \mathbf{b}, \mathbf{c}$, respectively. Scale bar $=25 \mu \mathrm{m}$

decrease of $\mathrm{nNOS}^{+}$neurons $/ \mathrm{mm}^{2}$, when comparing AS with CS cultures.

\section{Discussion}

We have investigated the potential neuroprotection of nicotinamide on the consequences of perinatal asphyxia on several neuronal parameters assessed in organotypic cultures, including neurite atrophy and neuronal loss, effects reported by several in vivo (Chen et al. 1997a, b; Kohlhauser et al. 1999a, b) and in vitro (Morales et al. 2003; Klawitter et al. 2005) studies, mainly affecting dopaminergic systems.

Perinatal asphyxia produced a region-specific decrease of cell viability in vitro, affecting substantia nigra, showing above $30 \%$ increase in EthD- $1^{+}$cells. However, no such effect was seen in neostriatum or neocortex. Immunocytochemistry confirmed the vulnerability of the substantia nigra, demonstrating that there was a significant decrease of cells with a neuronal phenotype (by $\sim 50 \%$ ), as assayed with an antibody against the NR1 subunit of the NMDA receptor, considered as a universal marker for neuronal phenotype 


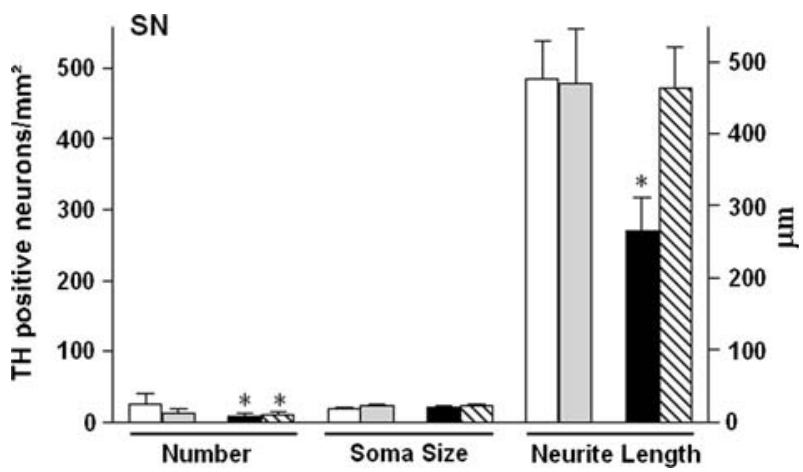

Fig. 6 Quantification of number (cells $\left./ \mathrm{mm}^{2}\right)$, soma size $(\mu \mathrm{m})$, and neurite length (maximum length, $\mu \mathrm{m}$ ) of $\mathrm{TH}^{+}$neurons in substantia nigra of cultures from saline-treated, caesarean-delivered (CS; open bars, $n=16-19)$; nicotinamide-treated, caesareandelivered ( $\mathrm{CN}$; grey bars, $n=8-13$ ); saline-treated, asphyxiaexposed (AS; filled bars, $n=17-19)$, and nicotinamide-treated, asphyxia-exposed (AN; hatched bars, $n=12-13$ ) animals at DIV 25. Multiple comparison analysis (Kruskal-Wallis's ANOVA, $H$ ) revealed significant differences between groups for cell number and neurite length $(H=10.58$, and $H=10.93, m, n=4,32$, respectively), allowing post-hoc comparisons. There was a statistically significant decrease of $\mathrm{TH}^{+}$cell number in cultures from $\mathrm{AS}$ and AN, compared to cultures from CS animals. A significant decrease of neurite length was also observed in cultures from AS, compared to CS animals. No decrease of neurite length was observed in cultures from AN animals. The data are means \pm SEM; $* p<0.05$ (Dunn's test)

(Petralia et al. 1994). This may include DA neurons. In agreement, there also was a significant decrease in the number of $\mathrm{TH}^{+}$cells $/ \mathrm{mm}^{2}$ following perinatal asphyxia $(>50 \%)$, as well as a decrease of the length of $\mathrm{TH}^{+}$processes, suggesting neurite atrophy. Surprisingly, following perinatal asphyxia, there was an increase in the number of $\mathrm{nNOS}^{+}$cells $/ \mathrm{mm}^{2}$ in substantia nigra (greater than fourfold), but a decrease in neostriatum $(>60 \%)$, and no apparent changes in neocortex. The main effect of nicotinamide was on striatal nNOS ${ }^{+}$ cells, preventing the decrease of the number of nNOS ${ }^{+}$ cells and neurite length produced by perinatal asphyxia. Nicotinamide also prevented the effect of perinatal asphyxia on $\mathrm{TH}^{+}$neurite length.

The present study addresses several important issues related to the effect of perinatal asphyxia. While the immediate effects of energy failure are related to functional impairment of pre-existing proteins (e.g. phosphorylation- and redox-related proteins), the long-term effects are related to alteration of gene expression, as shown by several reports (Dell'Anna et al. 1995; Labudova et al. 1999; Mosgoeller et al. 2000; Lubec et al. 2002), altering cell survival and neuritogenesis when oxygenation is re-established. Cell vulnerability depends upon the developmental stage of the particular neuronal system. Thus, while the number of dopaminergic cells in the substantia nigra is already established at birth (Olson and Seiger 1972; Loizou 1972; Seiger and Olson 1973; Voorn et al. 1988), there are, in vivo, waves of naturally occurring active postnatal DA neuron death (Oo and Burke 1997), therefore increasing the susceptibility of surviving neurons to energy failure, producing, as reported here, a decrease in the number of DA neurons $/ \mathrm{mm}^{2}$. Furthermore, although DA fibres invade the neostriatum before birth (Seiger and Olson 1973), a mature targeting is only achieved postnatally, when patches are replaced by a diffuse DA innervation pattern (Antonopoulos et al. 2002). The explanting procedure re-establishes the pattern of innervation to a primitive stage, forcing neurites to look for the corresponding targets, until plexuses with a patching appearance are established. The decrease of neurite length reported here perhaps reflects an impaired guidance by neighbouring cells rather than a deficit of intrinsic growth. It can be speculated that $\mathrm{TH}^{+}$neurite growth is affected by the observed increase of $\mathrm{nNOS}^{+}$cells $/ \mathrm{mm}^{2}$ locally in the substantia nigra, competing for guidance molecules provided by co-cultured regions. Indeed, it has been previously shown that there is an intriguing point-topoint synaptic interaction between $\mathrm{nNOS}^{+}$and $\mathrm{TH}^{+}$ neurons and processes in substantia nigra (HerreraMarschitz et al. 2000), and ventral striatum and cingulate cortex (Gomez-Urquijo et al. 1999), providing a morphological basis for a reciprocal interaction between dopamine and NO releasing neurons (Zhu and Luo 1992; West et al. 2002).

Ezquer et al. (2006) have recently reported an increase of nNOS expression in substantia nigra of rats exposed to neonatal hypoxia and reoxygenation. They suggested an inflammatory mechanism, mediated by tumoral necrosis factor- $\alpha(\mathrm{TNF}-\alpha)$ and NO generation by astrocytes through activation of the three NOS isoforms, nNOS, iNOS and endothelial NOS, as previously suggested (Cheng et al. 1994; Schauwecker et al. 1998). The decrease of $\mathrm{nNOS}^{+}$cells $/ \mathrm{mm}^{2}$ observed in neostriatum has also been reported by others, although this issue has been a subject of debate. Thus, Jiang et al. (1997) reported a reduction of NOS activity in neostriatum and other areas of the brain, but not in neocortex. In contrast, Peci-Saavedra and co-workers (Capani et al. 1997; Loidl et al. 1997), using nicotinamide adenine dinucleotide phosphate diaphorase (NADPH-d) as a histochemical marker for NO synthesizing neurons, reported that striatal neurons expressing NADPH-d showed a significant increment in soma size and dendrite length following subsevere and severe asphyxia (Loidl et al. 1997), as well as an increase of NADPH-d activity in blood vessels of striatal and cortical regions (Capani et al. 1997). In agreement, it has been shown in a gene hunting study, using subtrac- 
Fig. 7 Microphotographs illustrating $\mathrm{nNOS}^{+}$neurons (dark) in neostriatum of a triple organotypic culture from saline-treated, asphyxia-exposed (AS) animal at DIV 25

(a). b is a magnification of the horizontal rectangle depicted in a, showing a multipolar $\mathrm{nNOS}^{+}$neuron, with a medium soma size $(\sim 20 \mu \mathrm{m})$ and a neurite tree extending to different planes of the cultures. $\mathbf{c}$ is a magnification of the vertical rectangle in $\mathbf{a}$, showing a group of $\mathrm{nNOS}^{+}$ neurons $(\sim 18 \mu \mathrm{m})$. Scale bar $=25 \mu \mathrm{m}$
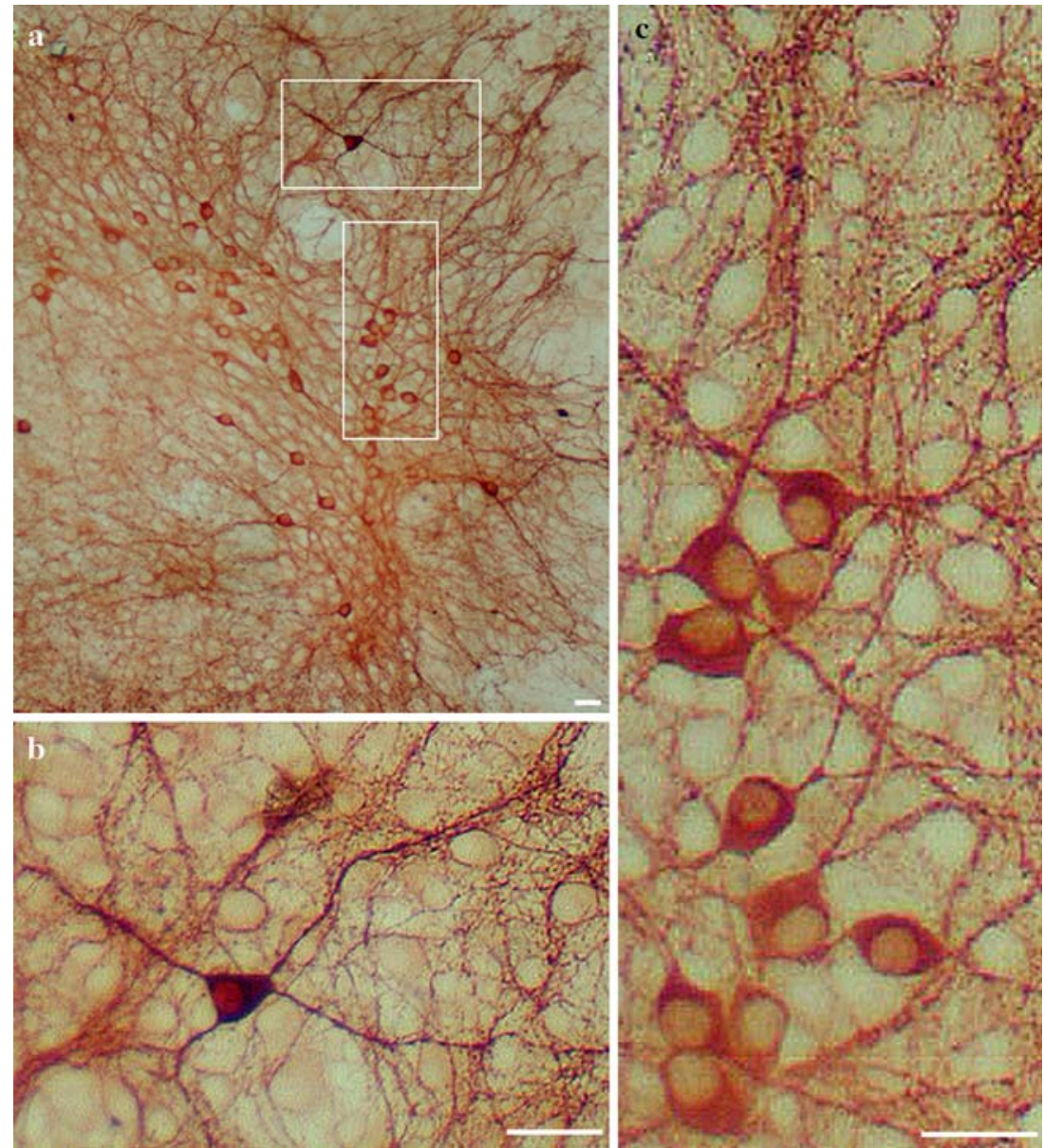
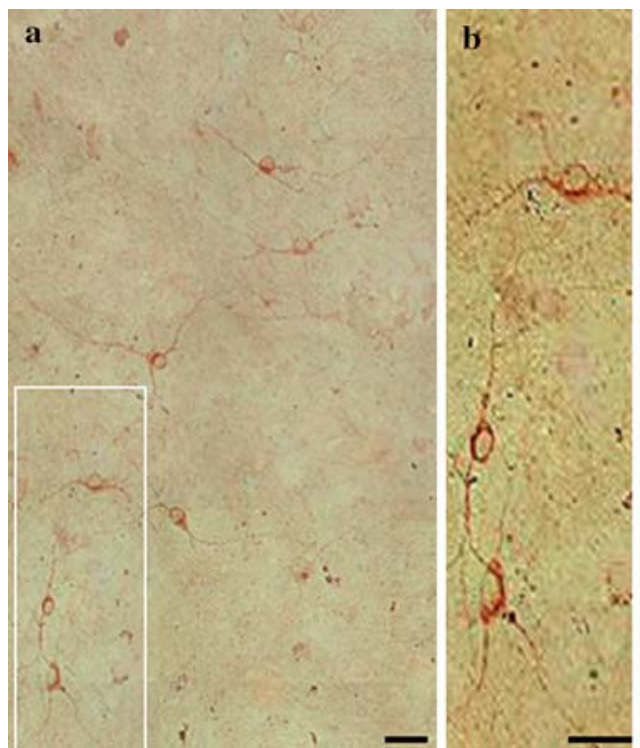

Fig. 8 Microphotographs illustrating NOSS $^{+}$neurons (dark) in substantia nigra of triple organotypic cultures from: saline-treated, caesarean-delivered control $(\mathrm{CS} ; \mathbf{a}, \mathbf{b})$; and saline-treated,

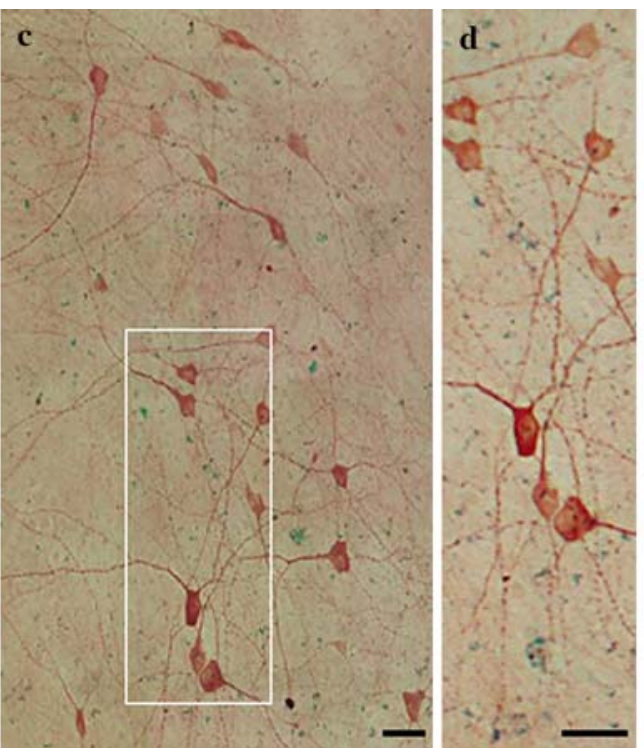

asphyxia-exposed (AS; $\mathbf{c}, \mathbf{d}$ ) animals at DIV 25. b, $\mathbf{d}$ are magnification of the rectangles in $\mathbf{a}, \mathbf{c}$, respectively. Scale bar $=25 \mu \mathrm{m}$ 
tive hybridization that NOS is about threefold upregulated in brain of rat pups exposed to perinatal asphyxia (Labudova et al. 1999; see also Lubec et al. 1999).

In the present study nicotinamide showed no effect on cell viability tested in vitro, nor on any other parameters measured in the substantia nigra, apart from an increased length of $\mathrm{TH}^{+}$neurites. A modest increase of $\mathrm{NR}^{+}$cells $/ \mathrm{mm}^{2}$ was only observed in neocortex. However, a robust effect was observed in neostriatum, where the number of $\mathrm{nNOS}^{+}$cells $/ \mathrm{mm}^{2}$ was increased greater than fourfold in cultures from nicotinamide-treated, versus saline-treated, asphyxiaexposed animals, which was accompanied by an increase of $\mathrm{nNOS}^{+}$neurite length to control levels. There was a significant decrease in soma size of $\mathrm{nNOS}^{+}$ cells in substantia nigra of cultures from AN animals, an effect difficult to be explained, but perhaps related to inhibition of inflammatory signals (Koh et al. 2004).

The effect of nicotinamide on $\mathrm{TH}^{+}$neurites is in agreement with a recent report showing that the treatment prevents the asphyxia-dependent decrease of dopamine release monitored with in vivo microdialysis 3 months after birth (Bustamante et al. 2006).

Nicotinamide has been shown to protect against oxidative stress (Yan et al. 1999; Wan et al. 1999), ischemic injury and inflammation (Ducrocq et al. 2000; Sakakibara et al. 2000) in neonatal rat brain, by restoring NADH/NAD ${ }^{+}$depletion (see Maynard et al. 2001), but also by inhibiting PARP-1 overactivation (Zhang et al. 1995; see Virag and Szabo 2002).

Upon re-oxygenation, there is a cascade of biochemical events worsening the biological outcome elicited by a deficient metabolism. One of the biochemical events involves the PAR polymerase family, which is activated, whenever there is a risk for DNA damage. Indeed, the polymerase isoforms, PARP-1 and PARP2 , are immediately activated when the integrity of the genome is menaced and/or damaged (Kihara et al. 1994; Akhter et al. 2001; Amé and Spenlehauer de Murcia 2004). PARP-1 catalyzes the attachment of chains of PAR to a variety of nuclear proteins, including PARP-1 itself. When DNA damage is mild, PARP1 is involved in the maintenance of chromatin integrity (de Murcia and Menissier de Murcia 1994; Ying et al. 2005). Excessive activation of PARP-1 leads, however, to $\mathrm{NAD}^{+}$exhaustion and energy crisis (Berger 1985), and to a caspase-independent apoptosis, via translocation of AIF to the nucleus, initiating nuclear condensation (Jiang et al. 1996; Yu et al. 2002; Hong et al. 2004). In agreement, we have reported that perinatal asphyxia leads to delayed neuronal death, mainly affecting neostriatum and neocortex (Dell'Anna et al. 1997).
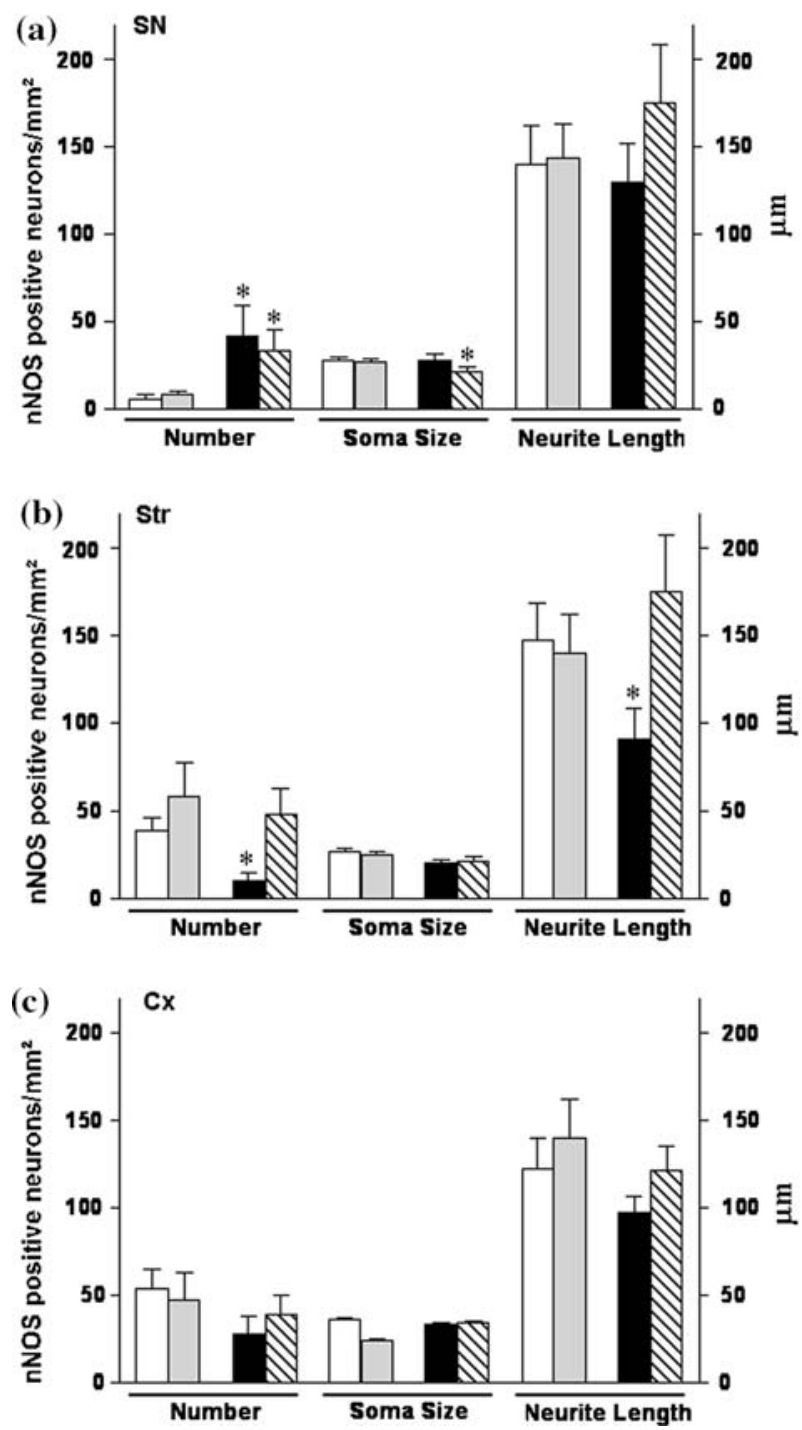

Fig. 9 Quantification of number (cell $\left./ \mathrm{mm}^{2}\right)$, soma size $(\mu \mathrm{m})$, and neurite length (maximum length, $\mu \mathrm{m}$ ) of NOOS $^{+}$neurons in: substantia nigra (SN); neostriatum (Str), and neocortex (Cx) of organotypic triple cultures from saline-treated, caesarean-delivered (CS; opened bars, $n=11-13$ ); nicotinamide-treated, caesareandelivered (NC; grey bars, $n=6-7$ ); saline-treated, asphyxiaexposed (AS; filled bars, $n=7-9$ ), and nicotinamide-treated, asphyxia-exposed (AN; hatched bars, $n=9$ ) animals. Multiple comparison analysis (Kruskal-Wallis's ANOVA, $H$ ) revealed significant differences between groups for cell number and soma size $(H=39.54 ; H=44.25, m, n=4,44$, respectively $)$, allowing post-hoc comparisons. There was a significant increase of the number of $\mathrm{nNOS}^{+}$cells in $\mathrm{SN}$ of cultures from AS and $\mathrm{AN}$ animals. In contrast, there was a significant decrease in the number of $\mathrm{nNOS}^{+}$cells in Str of cultures from AS animals. That decrease was prevented in Str of cultures from AN animals. There was a significant decrease in soma size of $\mathrm{nNOS}^{+}$cells in $\mathrm{SN}$ of cultures from AN animals. nNOS ${ }^{+}$neurite length was decreased in Str of cultures from AS, but not from AN animals. The data are means \pm SEM; $* P<0.05$ (Dunn's test)

The strongest evidence for the hypothesis that PARP-1 inhibition can constitute a target for neuroprotection following hypoxic or ischemic insults is from 
studies showing that the outcome of ischemic injury is decreased in PARP(-/-) mice (Eliasson et al. 1997), supporting previous evidence that PARP inhibitors, with increasing degrees of potency, decrease brain damage and improve the neurological outcome of perinatal brain injury (Zhang et al. 1995; Ducrocq et al. 2000; Sakakibara et al. 2000). While nicotinamide has been proposed to protect against brain injury (Yan et al. 1999; Wan et al. 1999; Sakakibara et al. 2000; Ducrocq et al. 2000), its usefulness has been challenged because of its low potency, limited cell uptake and short cell viability, stimulating the investigation for more specific compounds inhibiting PARP-1 overactivation (Takahashi et al. 1999; Ducrocq et al. 2000; Abdelkarim et al. 2001; Kamanaka et al. 2004; Iwashita et al. 2004; Nakajima et al. 2005).

The present results support, however, the idea of nicotinamide as an interesting molecule. Nicotinamide pharmacodynamic properties can provide advantages over more selective compounds, in particular its low potency to inhibit PARP-1. This quality can be useful when the compound is administered to developing animals, because the drug will only antagonise the effect of PARP-1 overactivation, without impairing DNA repair and cell proliferation. Furthermore, nicotinamide can constitute a lead for exploring compounds with similar pharmacological profile.

In conclusion, nicotinamide prevents long-term neuronal deficits induced by perinatal asphyxia, mainly observed in neostriatum, on $\mathrm{NOS}^{+}$neurons, but also on $\mathrm{TH}^{+}$neurite growth. The effect of nicotinamide enlightens the enzyme PARP-1 as a novel target for neuroprotection following insults involving energy failure.

Acknowledgments This study was supported by grants from FONDECYT-Chile (1030521) and DID (I2-02/8-2). We are grateful for the excellent technical and secretarial help from Mr. Juan Santibañez, Ms. Carmen Almeyda and Ms. Ana Maria Mendez. We thank Prof. Piers Emson, Barbrahan Institute, Cambridge University, Cambridge, UK for generous supply of NOS antiserum.

\section{References}

Abdelkarim GE, Gertz K, Harms C, Katchanov J, Dimagl U, Szabo C, Endres M (2001) Protective effects of PJ34, a novel, potent inhibitor of poly(ADP-ribose) polymerase (PARP) in vitro and in vivo models of stroke. Int J Mol Medicine 7:255-260

Akhter W, Ashraf QM, Zanelli SA, Mishra OP, Delivoria-Papadopoulus M (2001) Effect of graded hypoxia on cerebral cortical genomic DNA fragmentation in newborn piglets. Biol Neonate 79:187-193

Amé J-C, Spenlehauer de Murcia G (2004) The PARP superfamily. BioEssays 26:882-893

Antonopoulos J, Dori I, Dinopoulos A, Chiotelli M, Parnavelas JG (2002) Postnatal development of the dopaminergic system of the striatum in the rat. Neuroscience 110:245-256
Berger NA (1985) Poly (ADP-ribose) in the cellular response to DNA damage. Radiat Res 1001:4-15

Bustamante D, Goiny M, Åström G, Gross J, Andersson K, Herrera-Marschitz M (2003) Nicotinamide prevents the long-term effects of perinatal asphyxia on basal ganglia monoamine systems in the rat. Exp Brain Res 148:227-232

Bustamante D, Morales P, Torres Pereyra J, Goiny M, HerreraMarschitz M (2006) Nicotinamide prevents the effect of perinatal asphyxia on dopamine release evaluated with in vivo microdialysis three months after birth. Exp Brain Res (Oct. 19; Epub)

Capani F, Loidl F, Lopez-Costa JJ, Selvin-Testa, Saavedra JP (1997) Ultrastructural changes in nitric oxide synthase immunoreactivity in the brain of rats subjected to perinatal asphyxia: neuroprotective effects of cold treatment. Brain Res 775:11-23

Chen Y, Herrera-Marschitz M, Bjelke B, Blum M, Gross J, Andersson K (1997a) Perinatal asphyxia-induced changes in rat brain tyrosine-hydroxylase-immunoreactive cell body number: effects of nicotine treatment. Neurosci Lett 221:77-80

Chen Y, Engidawork E, Loidl F, Dell'Anna E, Goiny M, Lubec G, Andersson K, Herrera-Marschitz M (1997b) Short- and long-term effects of perinatal asphyxia on monoamine, amino acid and glycolysis product levels measured in the basal ganglia of the rat. Dev Brain Res 104:19-30

Cheng HW, Jiang T, Brown SA, Pasinetti GM, Finch CE, McNeil TH (1994) Response of striatal astrocytes to neuronal deafferentiation: and immunocytochemical and ultrastructural study. Neuroscience 62:425-439

Chiappe-Gutierrez M, Kitzmueller E, Labudova O, Fuerst G, Hoeger H, Hardmeier R, Nohl H, Gille L, Lubec B (1998) mRNA levels of the hypoxia inducible factor (HIF-1) and DNA repair genes in perinatal asphyxia of the rat. Life Sci 63:1157-1167

Dell'Anna E, Chen Y, Loidl F, Andersson K, Luthman J, Goiny M, Rawal R, Lindgren T, Herrera-Marschitz M (1995) Shortterm effects of perinatal asphyxia studied with Fos-immunocytochemistry and in vivo microdialysis in the rat. Exp Neurol 131:279-287

Dell'Anna E, Chen Y, Engidawork E, Andersson K, Lubec G, Luthman J, Herrera-Marschitz M (1997) Delayed neuronal death following perinatal asphyxia. Exp Brain Res 1151:105-115

De Murcia G, Menissier de Murcia J (1994) Poly(ADP-ribose) polymerase: a molecular nick-sensor. TIBS 19:172-176

Ducrocq S, Benjelloun N, Plotkine M, Ben-Ari Y, CharriautMarlangue C (2000) Poly(ADP-ribose) synthase inhibition reduces ischemic injury and inflammation in neonatal rat brain. J Neurochem 74:2504-2511

Eliasson MJ, Sampei K, Madier AS, Hurn PD, Traystman RJ, Bao J, Pieper A, Wang ZQ, Dawson TM, Snyder SH (1997) Poly(ADP-ribose) polymerase gene disruption renders mice resistant to cerebral ischemia. Nat Med 3:1089-1095

Ezquer ME, Valdez SR, Seltzer AM (2006) Inflammatory responses of the substantia nigra after acute hypoxia in neonatal rats. Exp Neurol 171:391-398

Foster GA (1998) Chemical neuroanatomy of the prenatal rat brain. Oxford University Press, New York

Gähwiler BH (1981) Organotypic monolayer cultures of nervous tissue. J Neurosci Methods 4:329-342

Gomez-Urquijo S, Hökfelt T, Ubink R, Lubec G, Herrera-Marschitz M (1999) Neurocircuitries of the basal ganglia studied in organotypic cultures: focus on tyrosine hydroxylase, nitric oxide synthase and neuropeptide immunocytochemistry. Neuroscience 94:1133-1151

Green A, Prager A, Stoudt PM, Murray D (1992) Relationships between DNA damage and the survival of radiosensitive mutant 
Chinese hamster cell lines exposed to gamma-radiation. Part 1 intrinsic radiosensitivity. Int J Radiat Biol 61:465-472

Hassa PO, Hottinger MO (1999) A role of poly(AFP-ribose) polymerase in $\mathrm{NF}-\kappa \mathrm{B}$ transcriptional activation. Biol Chem 380:953-959

Herrera-Marschitz M, loidl CF, Andersson K, Ungerstedt U (1993) Prevention of mortality induced by perinatal asphyxia: hypothermia or glutamate antagonism? Amino Acids 5:413419

Herrera-Marschitz M, Kohlhauser C, Gomez-Urquijo S, Ubink R, Goiny M, Hökfelt T (2000) Excitatory amino acids, monoamine, and nitric synthase systems in organotypic cultures: biochemical and immunohistochemical analysis. Amino Acids 19:33-43

Hong SJ, Dawson TM, Dawson VL (2004) Nuclear and mitochondrial conversations in cell death: PARP-1 and AIF signalling. TIPS 25:259-264

Hortobagyi T, Görlach C, Benyo ZL, Lacza Z, Hortobagyl S, Wahl M, Harkany T (2003) Inhibition of neuronal nitric oxide synthase-mediated activation of poly(ADP-ribose) polymerase in traumatic brain injury: Neuroprotection by 3 aminobenzamide. Neuroscience 121:983-990

Hwang J-J, Choi S-Y, Koh J-Y (2002) The role of NADPH oxidase, neuronal nitric oxide synthase and poly(ADP-ribose) polymerase in oxidative neuronal death induced in cortical cultures by brain-derived neurotrophic factor and neurotrophin-4/5. J Neurochem 82:894-902

Iwashita A, Tojo N, Matsuura S, Yamazaki S, Kamijo K, Ishida J, Yamamoto H, Hattori K, Matsuoka N, Mutoh S (2004) A novel and potent poly(ADP-ribose) polymerase-1 inhibitor, FR247304 (5-chloro-2-[3-(4-phenyl-3,6-dihydro-1(2H0-pyridinyl)propyl]-4(3H)-quinazolinone) attenuates neuronal damage in vitro and in vivo models of cerebral ischemia. J Pharmacol Exp Ther 310:425-436

Jiang B-H, Rue E, Wang GL, Roe R, Semenza GL (1996) Dimerization, DNA binding, and transactivation properties of hypoxia-inducible factor 1. J Biol Chem 271:17771-17778

Jiang K, Kim S, Murphy S, Song D, Pastuszko A (1997) Effect of hypoxia and reoxygenation on regional activity of nitric oxide synthase in brain of newborn piglets. Neurosci Lett 206:199-203

Kamanaka Y, Kondo K, Ikeda Y, Kamoshima W, Kitajima T, Suzuki Y, Nakamura Y, Umemura K (2004) Neuroprotective effects of ONO-1924H, an inhibitor of poly ADP-ribose polymerase (PARP), on cytotoxicity of PC12 cells and ischemic cerebral damage. Life Sci 76:151-162

Kihara S, Shiraishi T, Nakagawa S, Toda K, Tabuchi K (1994) Visualization of DNA double strand breaks in the gerbil hippocampal CA1 following transient ischemia. Neurosci Lett 175:133-136

Klawitter V, Morales P, Johansson S, Bustamante D, Goiny M, Gross J, Luthman J, Herrera-Marschitz M (2005) Effect of perinatal asphyxia on cell survival, neuronal phenotype and neurite growth evaluated with organotypic triple cultures. Amino Acids 28:149-155

Klawitter V, Morales P, Bustamante D, Goiny M, Herrera-Marschitz M (2006) Plasticity of the central nervous system (CNS) following perinatal asphyxia: does nicotinamide provide neuroprotection? Amino Acids (July 31 Epub)

Koh S-H, Park Y, Song CW, Kim JG, Kim K, Kim J, Kim M-H, Lee SR, Kim DW, Yu H-J, Chang D, Hwang SJ, Kim SH (2004) The effect of PARP inhibitor on ischemic cell death, its related inflammation and survival signals. Eur J Neurosci 20:1461-1472

Kohlhauser C, Mosgoeller W, Hoeger H, Lubec G, Lubec B (1999a) Cholinergic, monoaminergic and glutamatergic changes following perinatal asphyxia in the rat. Cell Mol Life Sci 55:1491-1501

Kohlhauser C, Kaehler S, Mosgoeller W, Singewald N, Kouvelas D, Prast H, Hoeger H, Lubec B (1999b) Histological changes and neurotransmitter levels three months following perinatal asphyxia in the rat. Life Sci 64:2109-2124

Labudova O, Schüller E, Yeghiazarjan K, Kitzmueller E, Hoeger H, Lubec G, Lubec B (1999) Genes involved in the pathophysiology of perinatal asphyxia. Life Sci 64:18311838

Loidl CF, Capani F, Lopez-Costa JJ, Selvin-Testa A, Lopez EM, Goldstein J, Pecci-Saavedra J (1997) Short-term changes in NADPH-diaphorase reactivity in rat brain following perinatal asphyxia. Mol Chem Neuropathol 31:301-316

Loizou LA (1972) The postnatal ontogeny of monoamine-containing neurones in the central nervous system of the albino rat. Brain Res 40:395-418

Lubec B, Kozlov AV, Krapbenbauer K, Berger A, Hoeger H, Herrera-Marschitz M, Nohl H, Koeck T, Lubec G (1999) Nitric oxide and nitric oxide synthase in the early phase of perinatal asphyxia of the rat. Neuroscience 93:1017-1023

Lubec B, Labudova O, Hoeger H, Kirchner L, Lubec G (2002) Expression of transcription factors in the brain of rats with perinatal asphyxia. Biol Neonate 81:266-278

Maynard KI, Ayoub IA, Shen CC (2001) Delayed multidose treatment with Nicotinamide extends the degree and the duration of neuroprotection by reducing infarction and improving behavioral scores up to two weeks following transient focal cerebral ischemia in Wistar rats. Ann NY Acad Sci 939:416-424

Mishra OP, Akhter W, Ashraf QM, Delivoria-Papadopoulus M (2003) Hypoxia-induced modification of poly (ADP-ribose) polymerase and DNA polymerase $\beta$ activity in cerebral cortical nuclei of newborn piglets: role of nitric oxide. Neuroscience 119:1023-1032

Morales P, Klawitter V, Johansson S, Huaiquin P, Barros VG, Avalos AM, Fiedler J, Bustamante D, Gomez-Urquijo S, Goiny M, Herrera-Marschitz M (2003) Perinatal asphyxia impairs connectivity and dopamine neurite branching in organotypic triple culture from rat substantia nigra. Neurosci Lett 348:175-179

Mosgoeller W, Kastner P, Fang-Kircher S, Kitzmueller E, Hoeger H, Seitler P, Labudova O, Lubec B (2000) Polymerase and nucleolar structure in perinatal asphyxia of the rat. Exp Neurol 161:174-182

Nagayama T, Simon RP, Chen D, Henshall DC, Pei W, Stetler RA, Chen J (2000) Activation of poly(ADP-ribose) polymerase in the rat hippocampus may contribute to cellular recovery following sublethal transient global ischemia. J Neurochem 74:1636-1645

Nakajima H, Kakui N, Ohkuma K, Ishikawa M, Hasegawa T (2005) A newly synthesized poly(ADP-ribose) polymerase inhibitor, DR2313[2-methyl-3,5,7,8-tetrahydrothiopyranol[4,3-d]-pyrimidine-4-one]: pharmacological profiles, neuroprotective effects and therapeutic time window in cerebral ischemia in rats. J Pharmacol Exp Ther 312:472-481

Olson L, Seiger $\AA$ (1972) Early prenatal ontogeny of central monoamine neurons in the rat: fluorescence histochemical observations. Z Anat Entwicklungsgesch 137:301-316

Oo TF, Burke RE (1997) The time course of the developmental cell death in phenotypically defined dopaminergic neurons of the substantia nigra. Dev Brain Res 98:191-196

Petralia RS, Yokotani N, Wenthold RJ (1994) Light and electron microscope distribution of the NMDA receptor subunit NMDAR1 in the rat nervous system using a selective antipeptide antibody. J Neuroscience 14:667-696 
Plenz D, Kitai ST (1996a) Organotypic cortex-striatum-mesencephalon cultures: the nigrostriatal pathway. Neurosci Lett 209:177-180

Plenz D, Kitai ST (1996b) Generation of high frequency oscillations in cortical circuits of somatosensory cortex cultures. J Neurophysiol 76:4001-4005

Plenz D, Herrera-Marschitz M, Kitai ST (1998) Morphological organization of the subthalamic nucleus-globus pallidus system studied in organotypic cultures. J Comp Neurol 397:437457

Sakakibara Y, Mitha AP, Ogilvy CS, Maynard KI (2000) Posttreatment with nicotinamide (vitamin $\mathrm{B}(3)$ ) reduces the infarct volume following permanent focal cerebral ischemia in female Sprague-Dawley and Wistar rats. Neurosci Lett 281:111-114

Saldeen J, Welsh N (1998) Nicotinamide-induced apoptosis in insulin producing cells is associated with cleavage of poly(ADP-ribose) polymerase. Mol Cell Endocrinol 139:99_ 107

Saldeen J, Tillmar L, Karlsson E, Welsh N (2003) Nicotinamideand caspase-mediated inhibition of poly(ADP-ribose) polymerase are associated with p53-independent cell cycle (G2) arrest and apoptosis. Mol Cell Biochem 243:113-122

Schauwecker PE, Cogen JP, Jiang T, Cheng HW, Collier TJ, McNeil TH (1998) Differential regulation of astrocytic mRNAs in the rat striatum after lesions of the cortex or substantia nigra. Exp Neurol 149:87-96

Seiger $\AA$, Olson L (1973) Late prenatal ontogeny of central monoamine neurons in the rat: fluorescence histochemical observations. Z Anat Entwicklungsgesch 140:281-318

Sung P, Bailly V, Weber C, Thompson LH, Prakash L, Prakash S (1993) Human xeroderma pigmentosum group D gene encodes a DNA helicase. Nature 365:852-855

Takahashi K, Pieper AA, Croul SE, Zhang J, Snyder SH, Greenberg JH (1999) Post-treatment with an inhibitor of
poly(ADP-ribose) polymerase attenuates cerebral damage in focal ischemia. Brain Res 829:46-54

Virag L, Szabo C (2002) The therapeutic potential of poly(ADPribose) polymerase inhibitors. Pharmacol Rev 54:375-429

Voorn P, Kalsbeck A, Jorritsma-Byham B, Groenewegen HJ (1988) The pre- and postnatal development of the dopaminergic cell groups in the ventral mesencephalon and the dopaminergic innervation of the striatum of the rat. Neuroscience 25:857-887

Wan FJ, Lin HC, Kang BH, Tseng CJ, Tung CS (1999) D-amphetamine-induced depletion of energy and dopamine in the rat striatum is attenuated by nicotinamide pretreatment. Brain Res Bull 50:167-171

West AR, Galloway MP, Grace AA (2002) Regulation of striatal dopamine neurotransmission by nitric oxide: effector pathways and signalling mechanisms. Synapse 44:227-245

Yan Q, Briehl M, Crowley CL, Payne CM, Bernstein H, Bernstein C (1999) The NAD+ precursors, nicotinic acid and nicotinamide upregulate glyceraldehyde-3-phosphate dehydrogenase and glucose-6-phosphate dehydrogenase mRNA in Jurkat cells. Biochem Biophys Res Commun 255:133-136

Ying W, Alano CC, Garnier P, Swanson RA (2005) NAD ${ }^{+}$as a metabolic link between DNA damage and cell death. J Neurosci Res 79:216-223

Yu SW, Poitras MF, Coombs C, Bowers WJ, Federoff HJ, Poirier GC, Dawson TM, Dawson VL (2002) Mediation of poly(ADP-ribose) polymerase-1 dependent cell death by apoptosis-inducing factor. Science 297:250-263

Zhang J, Pieper A, Snyder SH (1995) Poly(ADP-ribose) synthase activation: an early indicator of neurotoxic DNA damage. J Neurochem 65:1411-1414

Zhu X, Luo L (1992) Effect of nitroprusside (nitric oxide)on endogenous dopamine release from rat striatal slices. J Neurochem 59:932-935 